\title{
20I2: Decoding the Countercultural Apocalypse, edited by Joseph Gelfer
}

Sheffield: Equinox Publishing, 20I I | xi + 203 pages | ISBN: 978-I-84553-639-8 (hardback) £60.00

By the middle of $20 \mathrm{I}$, readers interested in an academic perspective on the veracity of popular beliefs in the apocalypse that the Mayans allegedly predicted to happen in 2012 had already in their disposal two

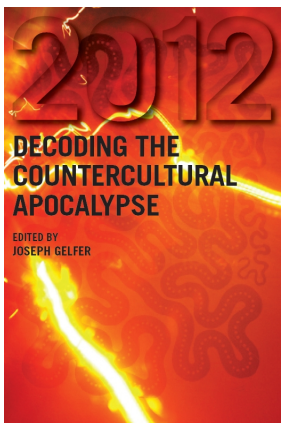
concise and accessible accounts published by scholars of Maya culture who convincingly argue against such claims. ${ }^{6}$ I remember in fact to have handed out, last January, in my class on Elements of Japanese Occult Thought, a copy of a newspaper article that appeared in the Washington Post (and republished in the Japan Times) in which Matthew Restall and Amara Solari repeat their argument that the ancient Maya predicted no apocalypse and that the global 2012 doomsday industry, or "20 I 2ology" as they call it, feeds on popular fascination with "ancient wisdom" and on the apocalyptic beliefs which remain central to Western religious traditions. On hearing, therefore, that a new book on the $20 \mathrm{I} 2$ phenomenon was to be edited by a researcher in religious studies, I looked forward to an analysis from a scholarly perspective that (understandably) had not been the central focus of the previous, Maya culture-centered publications. However, with a few notable exceptions, 20I2: Decoding the Countercultural Apocalypse was to me a disappointment, which, I believe, is due to the editor's relatively superficial perspective

${ }^{6}$ Matthew Restall and Amara Solari, 2012 and the End of the World: The Western Roots of the Maya Apocalypse (Lanham: Rowman \& Littlefield, 20 I I) and David Stuart, The Order of Days: The Maya World and the Truth about 2012 (New York: Harmony Books, 201 I). 
on the 2012 phenomenon as "a complex mosaic of interrelated elements-a historical legacy here, a conversation there-which often come together via synchronicities that many see themselves as evidence of the prophetic nature of 2012 " (3). I think that such an idea which de-emphasizes the common themes running through "20 I 2ology" has lead to a collection of papers, very uneven in content and style, whose target readership becomes rather impossible to identify.

The book is composed of a preface, ten chapters, the first of which is just a seven-page introduction (with the unimaginative title "Introduction"), followed by a section of notes to every chapter, and an index. I usually see no reason for not gathering all lists of references at the end of a book (rather than keeping them separated at the end of every chapter like in this case), but this may be a personal preference for a structure that allows an easier comparison of the sources used by the different authors. There is, however, a more serious editorial issue in chapter 3 which is partly based on an analysis of fairly complex paintings (particularly those on page 27) that are, unfortunately, printed so small that the author's discussion of them is very hard to follow.

The preface is written by Michael D. Coe, who, we learn is believed by "some Internet sites" (viii) to have started the whole $20 \mathrm{I} 2$ phenomenon by writing in 1966 about the Mayan calendar and its divisions according to eras composed of I 3 bakhtuns (or I 3 periods of 5,200 years). In his analysis, Coe suggested that at the end of the thirteenth bakhtun of our era which the Mayas placed on 24 December 20 I I (later revealed to have been Coe's miscalculation; the correct day being 2 I December 2012), the "Armageddon would overtake the degenerate peoples of the world and all creation" (cited on page viii). Although slightly apologetic ("I probably was out to scare my readers" [viii]), Coe's short description of how researchers had arrived at the correct date and his vague conclusion in which he does not refute his earlier argument but still criticizes creationists, "New Age portents and all other nonsense served up by Hollywood" for their "appetite for bogus revelation" (xi) does not really say much about what to expect from this collection of essays or about the reason why Coe was chosen to write the preface. He clearly does not believe that his writings lay at the origin of the 2012 phenomenon and counter-culturalism (mentioned in the subtitle of the book) does not seem to be his specialty.

Moving on to the short introductory chapter I by the editor, Joseph Gelfer, the reader is presented with a detailed chapter outline preceded by the author's account of the personal choices that led him to edit this book. 
Gelfer admits to have in the past "made a few dollars writing popular articles about themes intersecting with 2012" attacking thus, in a sense, what he calls "the myth of academic objectivity." Hence, he warns us that he has not sought to present a single view of the phenomenon, and that there are "internal contradictions" (3). And he concludes, by noting that "even if none of the predicted world-changing events take place, 20I 2 will forever be a classic example of the constantly evolving nature of the 'new' age, and no doubt prove to be an integral element of its manifestations" (7). While being reflexive and aware of one's positionality is the recommended approach to academic research, I strongly disagree here with Gelfer about academic objectivity being a myth. For me, such arguments are used to cover up the researcher's inability to put aside personal beliefs during his or her fieldwork. Being aware of one's position does not mean accepting one's 'inevitably' subjective analysis of primary data, but refers to one's understanding that one's analysis constantly needs corroboration and verification in order to produce 'reflexive knowledge.' If academic objectivity is a myth, perhaps the editor would have at least followed some elementary academic rules of structure, by noting, for example, what the objectives of this collection of papers are and what the framework of analysis consists of. If the book is supposed to fit within the ill-defined field of New Age studies, as the concluding sentence of the introductory chapter suggests, perhaps a substantial analysis of what the editor terms "the nature of the new age" would have made a good start point for a discussion on $20 \mathrm{I} 2$ as an undoubtedly significant belief among New Age circles around the world.

Fortunately for the reader, the next chapter by Robert K. Sitler, although an updated reprint of a paper published in 2006 in Nova Religio, provides an good summary of what the 2012 phenomenon entails. The author introduces the key figures behind the popularization of the belief that the winter solstice in 2012 will mark a fundamental transformation of humanity; the most famous being José Argüelles, "arguably the originator of the 20 I 2 phenomenon" (9), who in August 1987 became famous in New Age circles for organizing the Harmonic Convergence, the world's first synchronized meditation. As Sitler notes, the event accompanied Argüelles's best known book, The Maya Factor, in which the spiritual teacher claims that he had come to feel the spiritual presence of the Maya and that 1987 marked "a shift point

${ }^{7}$ Bruce L. Berg, Qualitative Research Methods for the Social Sciences, 6th ed. (London: Pearson Education, 2007), I79. 
of the galactic beam" that was to shift again in 2012 and lead to humanity's enlightenment. We learn that later Argüelles created his own version of the Maya calendar "which may be even more widely known outside of the Maya world that the actual ritual calendar" (го). The particular value of Sitler's paper lies, however, in his analysis of the impact the phenomenon has had on the Maya today. New Age teachers of Maya ancestry (or claiming so), such as Hunbatz Men and Alejandro Cirilo Pérez Oxlaj, have used their "authority" as Maya to make extraordinary claims about their peoples (Men, for example, claimed that the Maya had lived in other parts of the world [I 2]) and, sometimes cooperating with personalities such as Argüelles, seem to be participating in a "Maya cultural revitalization movement attempting to resuscitate key components of their heritage" (2I). Sitler shows that beliefs about a coming apocalypse and/or renewal appeal to local Maya who contextualize such ideas with their own experience of, for example, ongoing deforestation, the Guatemalan civil war, the 1976 Guatemala earthquake, the teachings of Christian missionaries, or even the recent Guatemalan presidential elections. "New Age tourism, globalization, and Maya immigration to the United States" (20) are also mentioned as factors contributing to the popularization of the $20 \mathrm{I} 2$ phenomenon among today's Maya population.

The next chapter by Mark Van Stone, a Mayanist scholar, makes a far less enjoyable read. The author goes into a very technical and authoritative-intone argument that can be summarized in two sentences: "we have too little fabric left to stitch together a coherent story" (35) and Maya seem to have manipulated dates and historical time-intervals "for optimum numerological and augural significance" (33). I can imagine someone interested in the most up-to-date findings about the Maya calendars being thrilled on reading this chapter, but the same explanations can be found in earlier publications in a much simpler tone. The 'debunking' character of this paper suffers, I believe, from a lack of depth in regards to, for example, what the vagueness of the Maya scriptures can tell us about their appropriateness as 'prophetic sources' for today's counterculture. The author mentions at some point the similarity between Mayan prophecies and Nostradamus's prophecies, but does not go further in his comparison. Van Stone seems more concerned with convincing the reader that the New Agers are wrong (a scientific fact that could have been stated in an introductory chapter) than engaged with the countercultural 'value' of the Maya sources.

The fourth chapter, "Mayanism Comes of (New) Age," is even more critical in tone and often repeats the same often-heard (but nevertheless accurate) 
observation: "unlike science, which seeks to optimize provisional explanations for empirically observed material phenomena, those working in the esoteric tradition are preoccupied with discovering and asserting ancient truths" (43). I wish that this introductory part would have been shorter, because the central focus of Hoopes's paper is rather fascinating, and begs for more comparative research with other New Age beliefs that, like "20 I zology," may seem new, but actually trace their roots to much older esoteric ideas. In this instance, the author argues that the "history of Mayanism can be traced through Spiritualism, Freemasonry, and Christian eschatology" (45) and presents several early examples of speculative theories about the Mayas. The most significant of these are three books published in the late nineteenth century by August Le Plongeon, a 33rd-degree Mason who claimed that "both ancient Egyptian culture and Freemasonry were derived from the Maya by way of the lost continent of Atlantis and that Jesus's last words on the Cross were spoken in Yucatec" (49). Hoopes repeats a well-known argument in the study of modern esotericism that ideas about an "Aryan supersociety" like those found in Le Plongeon's writings and in the more well-known work The Coming Race by Edward Bulwer-Lytton, were fundamental to the development of Helena Blavatsky's theosophical worldview, to Rudolf Steiner's anthroposophical movement, and to the more recent theories of New Agers such as Argüelles. Yet, Hoopes does not go further in his analysis. He, instead, chooses to offer a critique of both Coe's book, which he claims "crystallized Cold War anxieties" (53), and John Major Jenkins's work (which, surprisingly, reappears as the final chapter of this collection; hence I shall discuss it later in this review). I believe that criticism of these key figures of the 2012 phenomenon could have been placed elsewhere (most suitably just after their arguments in the preface and chapter io respectively), leaving space for more discussion on the early roots of the phenomenon.

The next chapter consisting of Pete Lentini's paper is probably, in academic terms, the weakest contribution to this collection. The problem lies in its self-referential research question: "this chapter addresses a main question of whether various actors have created a '20 I 2 Milieu' that has been syncretized from multiple sources of stigmatized knowledge" (62). The reader interested in religious studies would have already recognized here Lentini's reliance on Joseph Campbell's notion of "cultic milieu" and on Michael Barkun's categories of "stigmatized knowledge," which the author spends half of the chapter re-introducing to the audience, before moving on to an analysis of YouTube videos on the subject of "20I2." The reason that a book such as 
this exists, with chapters from such a variety of perspectives, is a proof in itself that there is a "20 2 milieu," and, furthermore, 20 I 2 figured already in Barkun's study of conspiracy theories, where it is introduced as an example of the "improvisational millenialism" of David Icke. ${ }^{8}$ Lentini's question does, hence, not really need any verification, but should rather form the basis for further exploration of the phenomenon. Unfortunately, the analysis of the YouTube videos does not achieve that, not only because of the ensuing lack of space for an appropriately developed argument, but also because the author does not reveal anything new that excellent general studies of the YouTube culture $^{9}$ have not yet already demonstrated, particularly in relation to the "diverse and often intersecting currents of thought" (77) that amateur online videos allow and to the "sensationalism and profit-orientation" (77) that they are subjected to.

In chapter 6, as its title "Chichén Itzá and Chicken Little" suggests, we return to the critical, 'debunking' tone of chapter 3, but here author Kristine Larsen goes straight into a clear and concise scientific account that, while decoding and negating one by one the apocalyptic scenarios that 20 I 20 logists adhere to, laments the public's lack of general knowledge and the "cosmophobia" (IO4) that the 2012 "frenzy" demonstrates. Rather than an argumentbased paper, Larsen's section reads, hence, like a scientific report, which, nevertheless enjoyably, shows how confirmation biases function to support pseudoscientific beliefs that are then used by the media, and particularly by sensationalist documentaries of such otherwise respected channels as the History Channel and Discovery Channel, to raise their audience rates. Larsen, however, convincingly argues, for example that a sudden magnetic polarity switch is not going to occur in 20I2, because "geological evidence strongly suggests that such an event takes thousands of years to complete" (90); and an unknown planet $\mathrm{X}$ is not going to collide with our planet in 2012 , because if such a body existed it could not be now as close to Earth as to affect it by 2012 (95). By the end of the chapter, the reader will thus feel satisfied with the clear scientific explanations offered by the author, but she or he may already wonder to whom would she or he recommend this book. Indeed, as I argued in the beginning of this review, despite the editor's warn-

${ }^{8}$ David Icke is another popular figure of New Age and conspiracy theories. See Michael Barkun, A Culture of Conspiracy: Apocalyptic Visions in Contemporary America (Berkeley: University of California Press, 2003), 173-74.

${ }^{9}$ See, for example, Micheal Strangelove, Watching YouTube: Extraordinary Videos by Ordinary People (Toronto: University of Toronto Press, 2010). 
ing that he has chosen to present various views on the 2012 phenomenon, making of this book not just a study of the phenomenon but also one of its components (3), the tone and style of each chapter differs so much from the rest that it is impossible to identify a target audience. While, for example, chapters 2 and 3 are of an academic level that is accessible to only informed readers in the respective disciplines of the authors (Sitler, for example, never explains the meaning and significance of the "Pleiades" in the New Age, and Van Stone's analysis assumes a basic knowledge about mesoamerican civilizations), chapters 4 and 5 are of an introductory, undergraduate level, and chapter 6 could have been part of a popular scientific magazine.

This variability in tone and content continues for the rest of the book. Chapter 7, for example, could be described as a movie review written by a scholar-fan of Roland Emmerich's 2009 film 2012. Andrea Austin knows undoubtedly a lot about the genre of end-of-the-world films and argues that "Emmerich builds luck, fate, and deity simultaneously into the same narrative twists and poignant tableaux, allowing for both secular and non-secular perspectives on the film's events, and yet in the process stirring a conversation that strikes deep to the philosophical heart of each" (I I 5 ). The author's argument is that both the film and the 2012 phenomenon share the same apophthegm: "live every day as if it were your last; take every chance" (I2 I) and that is why they appeal to popular imagination. Emmerich is famous for disaster movies, such as Independence Day (1996), Godzilla (1998), or The Day After Tomorrow (2004), which are usually appreciated more for special effects than the depth of the stories or the development of the characters, but Austin claims the opposite. She says, for example, that 20 I 2 somehow "repairs" America's image as isolationist and xenophobic by emphasizing the international cooperation in the face of disaster ( I I 2 ). The author also argues that the film offers a more complex, "realistic" scenario around the survivors who represent a moral dilemma, because most of them escape the catastrophe thanks to the tickets they were able to buy in secret from the rest of the population and which allowed them to board the giant ships/Arks (I I6). The problem with such analysis is that Austin does not convince us of anything else than the fact that the film could also be watched from the perspective she describes. Yet, we can perfectly imagine that some people may not have seen the same "philosophical depth." A look at the dedicated forum on the Internet Movie Database website ${ }^{10}$ shows, for example, that viewers

\footnotetext{
${ }^{10} \mathrm{http}: / /$ www.imdb.com/title/tt I I 90080/board/threads/ (accessed on 29 March 20 I 2).
} 
despised Emmerich's blatant message of "political correctness" which Austin applauds, but which a comment in the forum identifies as "racist" in the sense that the obvious attempt to include characters from all ethnicities excludes, as the message poster puts it, "Nordic" looking people. ${ }^{11}$ In any case, Austin's paper would have been much more useful in really "decoding" 20 I 2, if comments by those involved in the making of the film or at least of viewers had been taken into account in her analysis.

Graham St John's paper (chapter 8) on the significance of the 20 I 2 phenomenon in psytrance culture is one of the better papers in this collection. The author argues that we need to look more into the objectives of those who appropriate such millenarian beliefs and convincingly demonstrates that rather than the Maya culture or the scenarios about the end of the world, in psytrance music, which is "an electronic dance music culture (EDMC)" (I 24), "20I 2 offers a system of meaning and hopeful event horizon for the redress of personal and cultural crises" (I39). I would maybe not go as far as calling "spiritual activism," like St John does, words posted on a psytrance forum, such as " 2012 is just code for get your shit together people, we need to change gears and change direction on this planet." However, there is no doubt that despite this edited book's focus on the apocalyptism of the 2012 phenomenon, New Agers (at least in my country of specialization, Japan ) have been rather talking about a 2012 "Ascension," a more positive belief in humanity's alleged access to the "next stage on a spiritual level," to what is hoped will be a more equal, peaceful and green world. Although it may be argued that such optimistic interpretations stem from the non-Christian based culture in which they have become popular, they are not absent from European circles of New Agers, as, for example, a November 2009 post on a Greek webpage suggests. In any case, St John's paper is the only contribution that considers the non-apocalyptic aspect of the 2012 beliefs, a domain that certainly needs more study as it may be reflecting geographical and cultural divergences in the way the 2012 phenomenon manifests itself in non-American parts of the world.

In this sense, Gelfer's own study of 20 I 2 beliefs in Australasia (chapter 9) provides a welcome comparative analysis of the phenomenon from a region where, we learn, Argüelles has a firm base (I 49). New Zealand's "clean green" image ( 156$)$, together with a romanticisation of the land as "a new frontier"

${ }^{11} \mathrm{http}: / / \mathrm{www} . \mathrm{imdb} . \mathrm{com} / \mathrm{title} / \mathrm{tt} \mathrm{I}$ I $9008 \mathrm{o} /$ board/thread/I 95502665 ?d= $196753724 \& \mathrm{p}=$ I\#196753724 (accessed 29 March 2012). 
and of the aboriginal culture (1 52), have led to Australasia being perceived as holding a privileged role within the 2012 phenomenon (I 53 ). Gelfer observes, for example, that Maori creation myths have been re-interpreted to fit some 2012 catastrophe prophecies (I47) and Argüelles has now moved from the United States to New Zealand because its position near the south pole will allow him to "prepare for the transition" (I 56). Gelfer concludes that "it is difficult to imagine a uniquely Australasian element to the 2012 drama that is not at some level 'indigenous'" (I 57) and, by this statement, the author opens, I believe, the road to unexplored areas of research on the different ways 2012 engages in acts of cultural appropriation both within the Western world (201 2 in Greece, for example, has been linked to another local New Age belief in the existence of a generation of people with hidden capabilities called the "the Children of I983") and outside of it (in Japan, as I earlier argued, people talk rather of a "20 I 2 Ascension" that some link with a Shinto-inspired environmentalism).

This collection of papers could have ended (albeit, temporarily) the debate here. I would have still pointed out the variability in tone and content of the papers and lamented over the lack of engagement with 'ordinary' people's opinions about 2012, and with the cultural and regional variations pointed out by the last two chapters, but my appreciation of the book would have been higher than what it is now. The editor, however, decided for, I guess, what he perceives to be "objectivity's sake" or what he calls "a bridge between the academic and the non-academic communities" (7) to finish the collection with a section written by a known figure of the 2012 phenomenon, independent scholar John Major Jenkins. Sitler had already observed that "even if lacking in scientifically convincing evidence, Jenkins's $20 \mathrm{I} 2$ theories bolster the beliefs of many New Agers who are generally uninformed regarding astronomy and Maya culture" (I 5 ). And Hoopes furthers the criticism by arguing that inspired by Blavatsky (54), Jenkins claims that "ancient Maya beliefs were part of a 'Primordial Tradition' ... [and] reworks 'the story of $202_{2}$ ' and its 'truth' into justification for a self-help, motivational enterprise with great promise of commercial success" (55). Asking Jenkins to reply to these criticisms would have been an excellent idea, but Gelfer confesses to have not done so (6), and seems to have not even warned the author about the targeted readership, a constant issue in this collection. As a result, we end up with a paper of which most is an attack on the academic community against which Jenkins expresses feelings of bitterness and rejection. The author claims, for example, to "have consistently found that scholars are not 
well apprised of one or more disciplines that are necessary for understanding the interdisciplinary synthesis I have offered" (I I I). He also complains that his "comments are frequently assailed by multiple critics who nitpick over semantics and evade addressing the main points and evidence I offer" (I70). Finishing with a detailed analysis — which is almost impossible for the uninformed reader to follow-of a monument that seems to be at the center of the polemic between Maya scholars who consider it too eroded to study (see, for example, Van Stone on page 32 of this volume) and Jenkins who thinks the opposite, the final chapter of this book has clearly been used as a platform for Jenkins to attempt to convince scholars of Maya culture of his worth, and nothing else. It is unclear what we are meant to learn from this diatribe other than wishing that Jenkins had enrolled on a doctoral program and solved his issues of calendrical calculations within the community of researchers specializing on the subject. For the rest of us who are more interested in the impact and reception of the 2012 phenomenon, chapter ro would have better served the collection as a concluding section which could have, for example, pointed out the significance of the phenomenon in the study of contemporary millenarianism and suggested further paths of research on the glocalization of stigmatized beliefs.

In conclusion, for the scholar or student in the broad field of religious studies, 20I2: Decoding the Countercultural Apocalypse fills a gap in the study of the 2012 phenomenon, albeit clumsily. As pointed out in this review, the target readership is difficult to identify with some chapters written in an academic tone and others much too simple in their analysis to entice the interest of postgraduate researchers. For readers of Relegere who are aware of Sitler's paper in its first edition, I would suggest that they start reading the book from chapters 4, 8, and 9. For the rest of those who think about reading this collection, know that, as the only inter-disciplinary study of the 2012 phenomenon published to this day, you have nothing to lose.

Ioannis Gaitanidis White Rose East Asia Center and Kokugakuin University 